\title{
Increased Levels of S100A8/A9 in Patients with Peritonsillar Abscess: A New Promising Diagnostic Marker to Differentiate between Peritonsillar Abscess and Peritonsillitis
}

\author{
Christoph Spiekermann, ${ }^{1,2}$ Antonella Russo, ${ }^{2}$ Markus Stenner, ${ }^{1}$ Claudia Rudack, ${ }^{1}$ \\ Johannes Roth, ${ }^{2}$ and Thomas Vogl ${ }^{2}$ \\ ${ }^{1}$ Department of Otorhinolaryngology, Head and Neck Surgery, University Hospital Münster, Münster, Germany \\ ${ }^{2}$ Institute of Immunology, University Hospital Münster, Münster, Germany \\ Correspondence should be addressed to Christoph Spiekermann; christophotto.spiekermann@ukmuenster.de
}

Received 19 June 2017; Revised 22 August 2017; Accepted 24 August 2017; Published 17 October 2017

Academic Editor: Patrizia Cardelli

Copyright (c) 2017 Christoph Spiekermann et al. This is an open access article distributed under the Creative Commons Attribution License, which permits unrestricted use, distribution, and reproduction in any medium, provided the original work is properly cited.

\begin{abstract}
Peritonsillar abscess (PTA) is a very frequent reason for urgent outpatient consultation and otolaryngological hospital admission. Early, correct diagnosis and therapy of peritonsillar abscess are important to prevent possible life-threatening complications. Based on physical examinations, a reliable differentiation between peritonsillar cellulitis and peritonsillar abscess is restricted. A heterodimeric complex called calprotectin consists of the S100 proteins A8 and A9 (S100A8/A9) and is predominantly expressed not only in monocytes and neutrophils but also in epithelial cells. Due to its release by activated phagocytes at local sites of inflammation, we assumed S100A8/A9 to be a potential biomarker for peritonsillar abscess. We examined serum and saliva of patients with peritonsillitis, acute tonsillitis, peritonsillar abscess, and healthy controls and found significantly increased levels of S100A8/A9 in patients with PTA. Furthermore, we could identify halitosis, trismus, uvula edema, and unilateral swelling of the arched palate to be characteristic symptoms for PTA. Using a combination of these characteristic symptoms and S100A8/A9 levels, we developed a PTA score as an objective and appropriate tool to differentiate between peritonsillitis and peritonsillar abscess with a sensitivity of $92 \%$ and specificity of $93 \%$.
\end{abstract}

\section{Introduction}

The palatine tonsils are related to the mucosa-associated lymphatic tissue (MALT) of the upper respiratory tract. Immunologically, four important microcompartments can be defined: the crypt epithelium which consists of a nonuniform epithelium; the follicular germinal center; the mantle zone, which is characterized by a high density of lymphocytes; and the interfollicular area, populated by Tlymphocytes [1]. As a part of Waldeyer's ring, tonsils play an important role in nasopharyngeal immunity and present the first line in host defense against pathogens particularly in children. In some cases, however, they trigger severe head and neck infections causing life-threatening complications $[2,3]$. The most common severe head and neck infection is the peritonsillar abscess (PTA) which is a very frequent reason for nonelective otolaryngological hospital admission [4]. Extension of an acute tonsillitis or an infection of Weber's salivary glands in the supratonsillar fossa was discussed to be the associated pathomechanisms of PTA which is characterized by an accumulation of pus between the fibrous capsule of the palatine tonsil and the pharyngeal constrictor muscle $[5,6]$. Due to the level of the uvula tip, peritonsillar abscesses can be divided into superior and inferior types. With a percentage of $75 \%$, the superior type is described to be the more common sort of peritonsillar abscesses [3].

Bacteria could be detected in abscess aspirates in $98 \%$ of the cases and $76 \%$ of those cases showed a combination of anaerobic and aerobic isolates [7, 8]. Fusobacterium necrophorum and Prevotella were described to be the most frequent anaerobic bacteria, and Streptococcus pyogenes, 
Staphylococcus aureus, and Haemophilus influenzae were the common aerobic isolates from peritonsillar abscess [7-11].

Incisional drainage, needle aspiration, and tonsillectomy are common treatment strategies in peritonsillar abscesses. Indications of abscess tonsillectomy became more doubtful over the years because this procedure is associated with an increased risk of spread of infection and postoperative hemorrhage [3]. Thus, needle aspiration was established as a less invasive, alternative treatment approach for peritonsillar abscess with success rates between 72 and 95\% [12-14]. Recurrence of a peritonsillar abscess could be observed in $10-19 \%$ after needle aspiration and the need of multiple attempts for adequate abscess relief indicate the strains for the patients and the limitation of this therapeutic regime $[12,15]$. Incision and drainage of the peritonsillar abscess is considered to be the more definite but also more painful procedure [16]. Only medical therapy has been described to be as successful as initial surgical treatment in patients with less severe initial infection [4]. Due to these highly variable and partially expensive therapeutic regimes, the optimal treatment strategy of patients with PTA at reasonable cost level still remains controversial $[12,16]$.

Furthermore, there is a small group of patients who show symptoms suspicious of PTA such as trismus, uvula edema, and swelling of the arched palate. Still, aspiration or incisional drainage revealed no pus. In this group, diagnosis changed from PTA to peritonsillar cellulitis (PC), also known as peritonsillitis [17]. Reliable differentiation between PTA and PC is of great importance to avoid delay of the appropriate treatment and consequently life-threatening complications like airway obstruction, aspiration and pneumonia, or erosion of major vessels $[9,18]$. However, $50 \%$ of the PTA patients are treated by nonotolaryngologists and diagnosis based on clinical examination is associated with a sensitivity of $78 \%$ and a specificity of just $50 \%[13,18]$. Hence, objective criteria or biomarkers to identify patients with PTA and to discriminate PTA from PC, to assess the severity of infection, or to identify patients who benefit from medical or surgical treatment would be helpful but still remain desirable [14].

S100A8 and S100A9, also known as myeloid-related proteins 8 and 14 (MRP 8/14), are members of the S100-protein family and show proinflammatory activities in a variety of different diseases. Both proteins form heterodimers also known as calprotectin or tetramers in the presence of calcium ions and are not only predominantly expressed in monocytes and neutrophilic granulocytes but are also inducible in epithelial cells $[19,20]$. They are related to the group of danger-associated molecular patterns (DAMP) or alarmins and activate leukocytes via a toll-like receptor 4 (TLR4) pathway resulting in increased cytokine and chemokine expression and thereby trigger inflammatory reactions [21-23]. There have been several reports about the pivotal role of S100A8/A9 as a biomarker in inflammatory diseases like rheumatoid arthritis, acute myocardial infarction, or chronical inflammatory bowel diseases [24-26].

In this prospective study, we examined S100A8/A9 levels in the serum and saliva and its potential role as a promising and helpful biomarker to differentiate between acute tonsillitis (AT), PC, and PTA.

\section{Material and Methods}

2.1. Patients and Healthy Controls. This prospective study was performed in the Department of Otorhinolaryngology, Head and Neck Surgery, University Hospital Münster. 25 patients with acute tonsillitis (AT) (11 males, 14 females, $27.8 \pm 2.5$ years $[$ mean \pm SEM] $), 36$ patients suffering from peritonsillar abscess (19 males, 17 females, $34.4 \pm 2.8$ years), and 16 patients with peritonsillitis ( 8 males, 8 females, 34.8 \pm 4.8 years) were included. Peritonsillar abscess was diagnosed by needle aspiration, abscess drainage in local or tonsillectomy in common anesthesia. Patients with clinical presentation similar to PTA but negative needle aspiration, incision, or tonsillectomy without revealing any purulent fluid and a good response to systemic antimicrobial treatment were assigned to the peritonsillitis group. Diagnosis was proven retrospectively. Healthy volunteers $(n=15$, $32.9 \pm 10.5$ years) without any history of acute or recurrent tonsillitis served as controls. Symptoms and observations of the physical examination were documented during initial outpatient consultation. The study was approved by the institutional ethics committee [2015-217-f-S], and written informed consent was obtained from all subjects.

2.2. S100A8/A9 Sandwich ELISA of the Serum and Saliva Samples. Serum samples were centrifuged at $2000 \mathrm{~g}$ for 10 minutes within 2 hours after acquisition, and supernatant was aliquoted and stored at $-20^{\circ} \mathrm{C}$ until analysis. Saliva acquisition was performed with untreated Salivette ${ }^{\circledR}$ (Sarstedt, 51.1534) as described in the manufacturer's datasheet or by collecting saliva in a $50 \mathrm{ml}$ Falcon tube and centrifugation at $1000 \mathrm{~g}$ for 15 minutes. Supernatant was aliquoted and stored at $-20^{\circ} \mathrm{C}$. S100A8/A9 concentrations were measured with a sandwich enzyme-linked immunosorbent assay (ELISA) for human S100A8/A9 as described earlier [27].

2.3. Bead-Based Immunoassay. Quantification of cytokines/ chemokines in serum and saliva was performed with the LEGENDplex ${ }^{\mathrm{TM}}$ assay "Human Inflammation Panel" (BioLegend) as described in the manufacturer's manual. The "Human Inflammation Panel" allows simultaneous measurement of IL-1 $\beta$, IL8, and other cytokines and chemokines. Fluorescent signal intensities were detected by $\mathrm{NAVIOS}^{\mathrm{TM}}$ Flow Cytometer (Beckmann Coulter).

2.4. Laboratory Parameters. As common inflammatory parameters, $\mathrm{C}$ reactive protein $(\mathrm{CRP},[\mathrm{mg} / \mathrm{dl}])$ and whole white blood cells $\left[\times 10^{3} / \mu l\right]$ were analyzed by clinical routine methodology.

2.5. Histological and Immunohistochemical (IHC) Analyses. Tonsils of 10 patients undergoing tonsillectomy because of peritonsillar abscess were used for further histological examinations. As a healthy control, hypertrophic tonsils of patients without any history of recurrent tonsillitis were obtained $(n=10)$. The tonsils were divided into two parts immediately after surgical extirpation. One-half was snapfrozen in liquid nitrogen and stored at $-80^{\circ} \mathrm{C}$, whereas the other part was fixed in $4 \%$ formalin for 2-3 days. Samples 


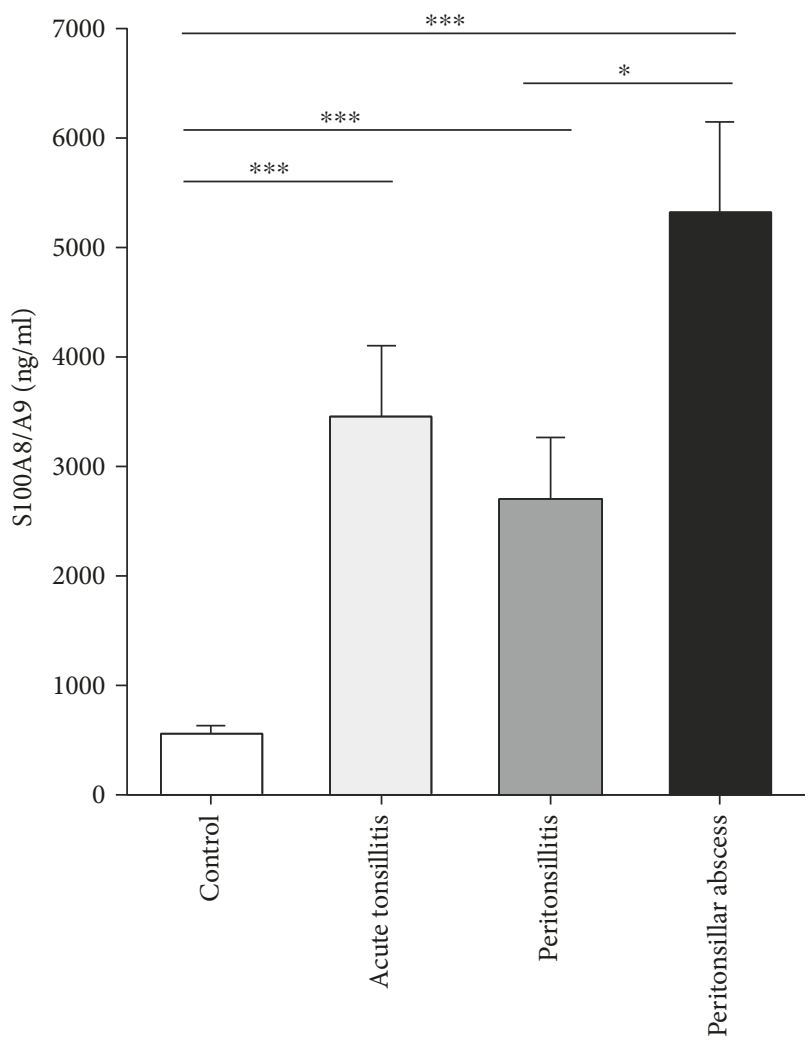

Diagnosis

(a)

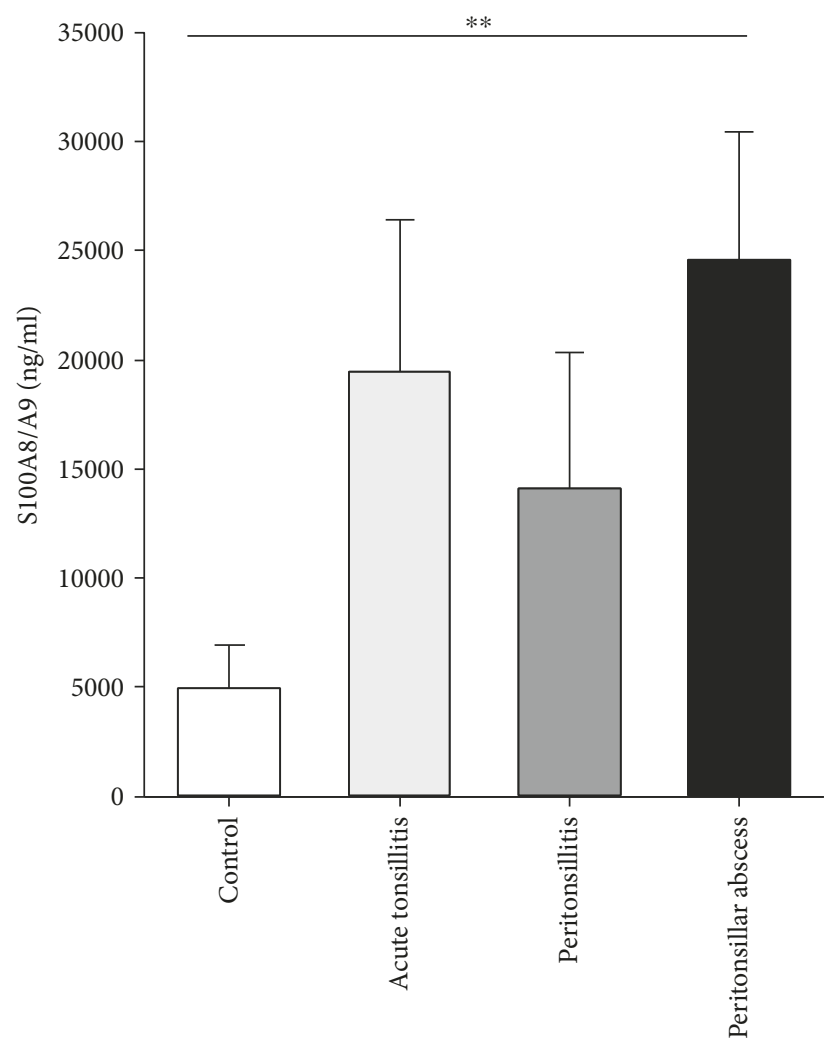

Diagnosis

(b)

FIGURE 1: S100A8/A9 levels in serum (a) and saliva (b) of controls and patients with acute tonsillitis, peritonsillitis, or peritonsillar abscess (mean \pm SEM). All entities show significantly increased serum levels compared to the controls. Furthermore, significantly higher S100A8/ A9 levels were detectable in sera of PTA patients compared to PC patients. There was a significant increase of salivary S100A8/A9 levels in patients with PTA compared to healthy controls $\left({ }^{*} p<0.05,{ }^{* *} p<0.01\right.$, and $\left.{ }^{* * *} p<0.001\right)$.

were embedded in paraffin and cut into $3 \mu \mathrm{m}$ thick sections followed by staining with hematoxylin and eosin. Furthermore, polyclonal rabbit anti-human S100A8 and anti-human S100A9 were used as primary antibodies and a biotinylated goat anti-rabbit IgG was added as a secondary antibody. Streptavidin peroxidase binding to biotin and its reaction with $3^{\prime}$-amino-ethyl-carbazole (Sigma, Germany) was utilized to identify S100A8/A9 localization in the tonsils. Additionally, nuclear counterstaining was performed with Mayer's hämalaun (Merck, Germany). Microphotographs of the complete tonsils were performed with the AxioVision MosaiX module for the Axio Observer Z1 microscope (Zeiss, Germany). Using a four-point Likert scale $(0=$ no staining, $1=$ mild staining, $2=$ moderate staining, and $3=$ high positive staining), semiquantitative analysis of the stained sections was performed by two independent investigators who were blinded regarding the diagnosis.

2.6. Statistical Analysis. Results are mean values \pm standard error of the mean (mean \pm SEM) or mean value \pm standard deviation $($ mean $\pm S D)$ as indicated in the figures. Chisquare analysis was used to identify possible relations between variables. Student $t$-test was used to detect significant differences in parametric results and Mann-Whitney $U$ test was performed to analyze differences between nonparametric groups. $p$ values $>0.05$ are considered not to be significant. Significant results are marked with asterisks $\left({ }^{*} p<0.05,{ }^{* *} p<0.01\right.$, and $\left.{ }^{* * *} p<0.001\right)$. The capacity of the model to differentiate between positive and negative results is illustrated by receiver operating characteristic (ROC) curves which allow calculation of area under the curve values ( $A$ values) and cut-off values. Discriminative power of the model is considered to be excellent with an $A$ value of $>0.9$, good $>0.8$, acceptable $>0.7$, and poor $>0.6$. Statistical analyses and creation of figures were performed with IBM $^{\circledR}$ SPSS $^{\circledR}$ Statistics 24 and SigmaPlot ${ }^{\circledR} 12$.

\section{Results}

3.1. Serum and Saliva Analysis. Systemic S100A8/A9 levels were increased in the serum of patients with acute tonsillitis compared to healthy controls $(3450 \pm 650 \mathrm{ng} / \mathrm{ml}$ versus $550 \pm 90 \mathrm{ng} / \mathrm{ml}, p<0.001)$. Furthermore, S100A8/A9 levels in patients with PTA $(5330 \pm 820 \mathrm{ng} / \mathrm{ml})$ were significantly higher than in patients with PC $(2710 \pm 550 \mathrm{ng} / \mathrm{ml}, p<0.05)$ and healthy controls $(p<0.001)$. There was no significant difference in S100A8/A9 levels in the sera between patients suffering from AT and PC or PTA (Figure 1(a)). Analysis of S100A8/A9 levels in saliva revealed no significant difference of the S100A8/A9 level in patients with AT 


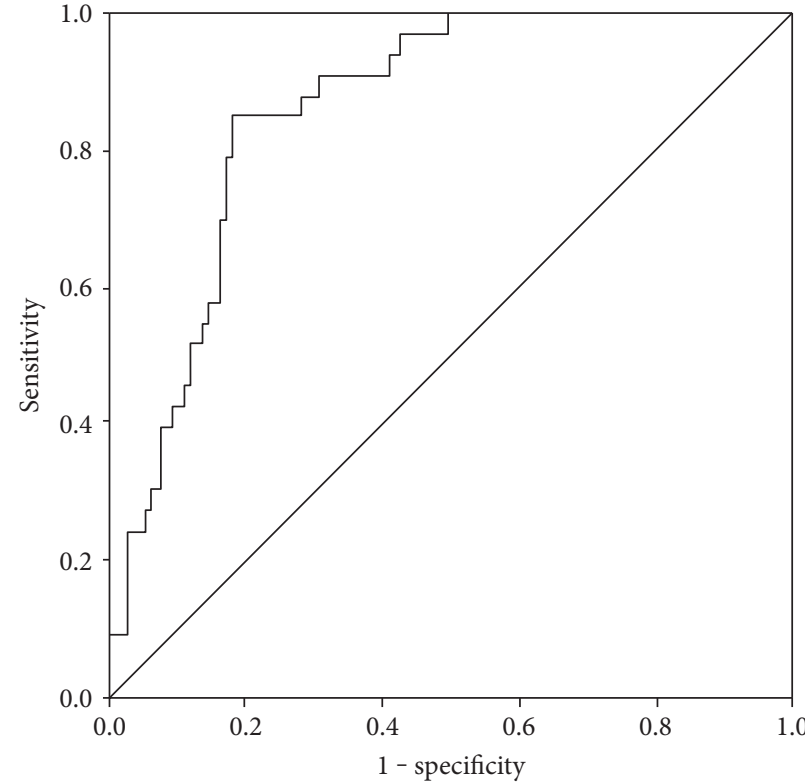

(a)

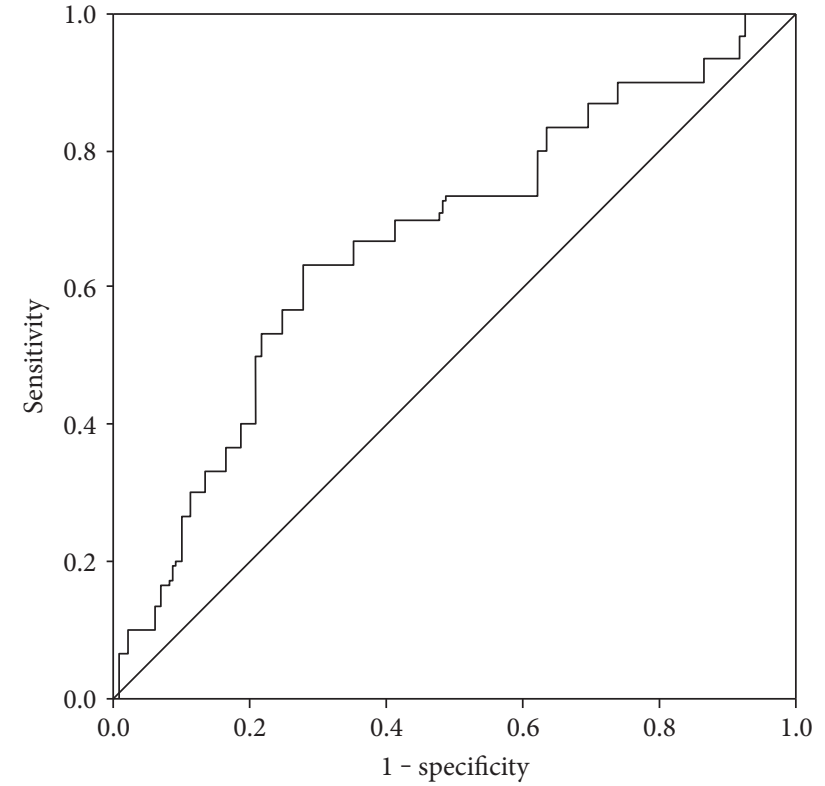

(b)

FIGURE 2: Receiver operating characteristic (ROC) curve in black, sensitivity on $y$-axis, and 1 - specificity on $x$-axis of S100A8/A9 in serum (a) and saliva (b) to identify patients with peritonsillar abscess. Grey: diagonal association line. Area under the curve $(a)=0.86$ and $(b)=0.67$.

$(19480 \pm 6920 \mathrm{ng} / \mathrm{ml}, p=0.08)$ or PC $(14110 \pm 6220 \mathrm{ng} / \mathrm{ml}$, $p=0.265)$ in comparison to the control group $(4940 \pm$ $1980 \mathrm{ng} / \mathrm{ml})$. However, the S100A8/A9 level in patients' saliva with peritonsillar abscess was significantly higher than in controls $(24590 \pm 5850 \mathrm{ng} / \mathrm{ml}, p=0.002$ ) (Figure $1(\mathrm{~b})$ ). Although a difference between the PTA and the PC group could be observed, the results were not significant $(p=0.087)$. Receiver operating characteristic (ROC) curve analysis provided a cut-off value of $8180 \mathrm{ng} / \mathrm{ml}$ in saliva (sensitivity $=0.63$, specificity $=0.72, p=0.019$ ) and $2550 \mathrm{ng} /$ $\mathrm{ml}$ in serum (sensitivity $=0.85$, specificity $=0.82, p=0.001$ ) for the existence of a peritonsillar abscess (Figures 2(a) and 2(b)). Neither levels of CRP (AT: $9.82 \pm 1.82 \mathrm{mg} / \mathrm{dl}$, PTA: $11.99 \pm 1.45 \mathrm{mg} / \mathrm{dl}$, and PC: $12.69 \pm 2.43 \mathrm{mg} / \mathrm{dl}, p>0.05)$ nor levels of white blood cells (AT: $13.38 \pm 0.90 \times 10^{3} / \mu \mathrm{l}$, PTA: $14.11 \pm 0.76 \times 10^{3} / \mu \mathrm{l}$, and PC: $\left.13.08 \pm 1.15 \times 10^{3} / \mu \mathrm{l}, p>0.05\right)$ showed any significant differences between the diagnosis groups (Figures 3(a) and 3(b)). Also, analysis of IL-1 $\beta$ and IL-8 in sera and saliva revealed no significant differences between the different cohorts (Figure 4).

\subsection{Histological and Immunohistochemical Examinations.} PTA is a localized process with an accompanying inflammatory reaction. Hence, to avoid misinterpretation of sectional S100A8/A9 expression, the MosaiX module was utilized to analyze each tonsil in toto. A normal microarchitecture with crypt epithelium, follicular germinal centers was observed in the tonsil from patients with PTA. Staining for S100A8/A9 was strongly positive in tonsils of patients with PTA $(3.30 \pm 0.23$ [mean score \pm SD] $)$ in contrast to hyperplastic tonsils without any history of tonsillitis (1.68 \pm 0.22 , $p<0.001)$. Above all, there was a sectional positive staining which might be due to abscess localization (Figures 5(a), 5(b), 5(c), and 5(d)).
3.3. Development of a PTA Score. Diagnosis of PTA is made by clinical examination and depends on subjective assessment of the clinician. Chi-square analysis revealed no significant relations between CRP $\left(\chi^{2}=124.05, p=0.431\right)$, leukocyte levels $\left(\chi^{2}=135.8, p=0.301\right)$, and patients with peritonsillar abscess. Symptoms like trismus $\left(\chi^{2}=30.39\right.$, $p<0.001)$, halitosis $\left(\chi^{2}=12.14, p=0.007\right)$, uvula edema $\left(\chi^{2}=27.01, p<0.001\right)$, and unilateral swelling of the arched palate $\left(\chi^{2}=60.11, p<0.001\right)$ were observed to be helpful clinical characteristics to identify peritonsillar abscess. Hence, by addition of one point for each symptom and for S100A8/A9 levels above the cut-off value of $2550 \mathrm{ng} / \mathrm{ml}$ in serum or $8180 \mathrm{ng} / \mathrm{ml}$ in saliva, a PTA score $\left(S_{\mathrm{PTA}}\right)$ with the lowest value of 0 and a maximum value of 6 points was developed (Table 1). PTA $\left(S_{\mathrm{PTA}}=3.84 \pm 0.15, p<0.001\right)$, PC $\left(S_{\mathrm{PTA}}=2.13 \pm 0.38, p<0.001\right)$, and $\mathrm{AT}\left(S_{\mathrm{PTA}}=0.93 \pm 0.22\right.$, $p=0.002)$ showed significantly increased $S_{\mathrm{PTA}}$ values in contrast to the control group $\left(S_{\mathrm{PTA}}=0.2 \pm 0.11\right)$. Furthermore, the differences between AT and PTA or PC were significant (PTA: $p<0.001$, PC: $p=0.007$ ) as well as the difference between patients suffering from PTA and PC $(p<0.001)$ (Figure 6(a)). A ROC curve analysis revealed a cut-off value of 2.5 (sensitivity $=0.92$, specificity $=0.93, p<0.001$ ) for the existence of a peritonsillar abscess (Figure 6(b)). The likelihood of PTA increases with higher $S_{\mathrm{PTA}}$ values (Table 2). For $S_{\mathrm{PTA}}$ values $\geq 3$, the overall probability of PTA is about $89.2 \%$.

\section{Discussion}

Several studies analyzed the influence of lymphocytes and the adaptive immune system on acute and recurrent tonsillitis and the triggering pathogens $[2,5,11]$. To our knowledge, 


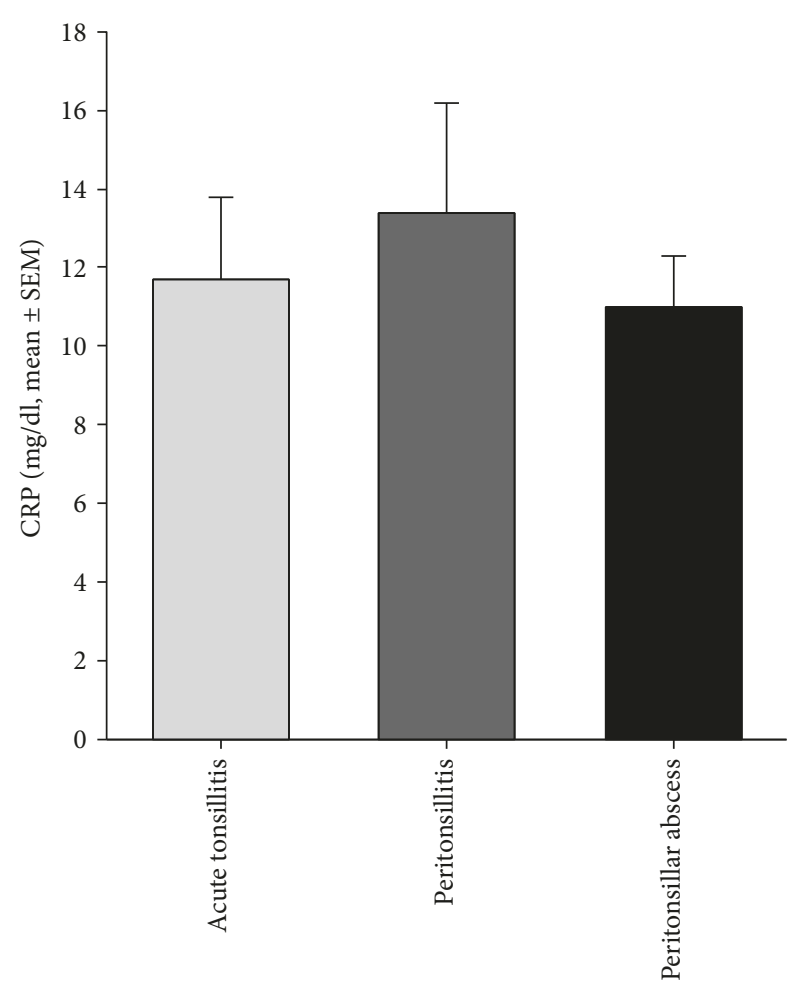

Diagnosis

(a)

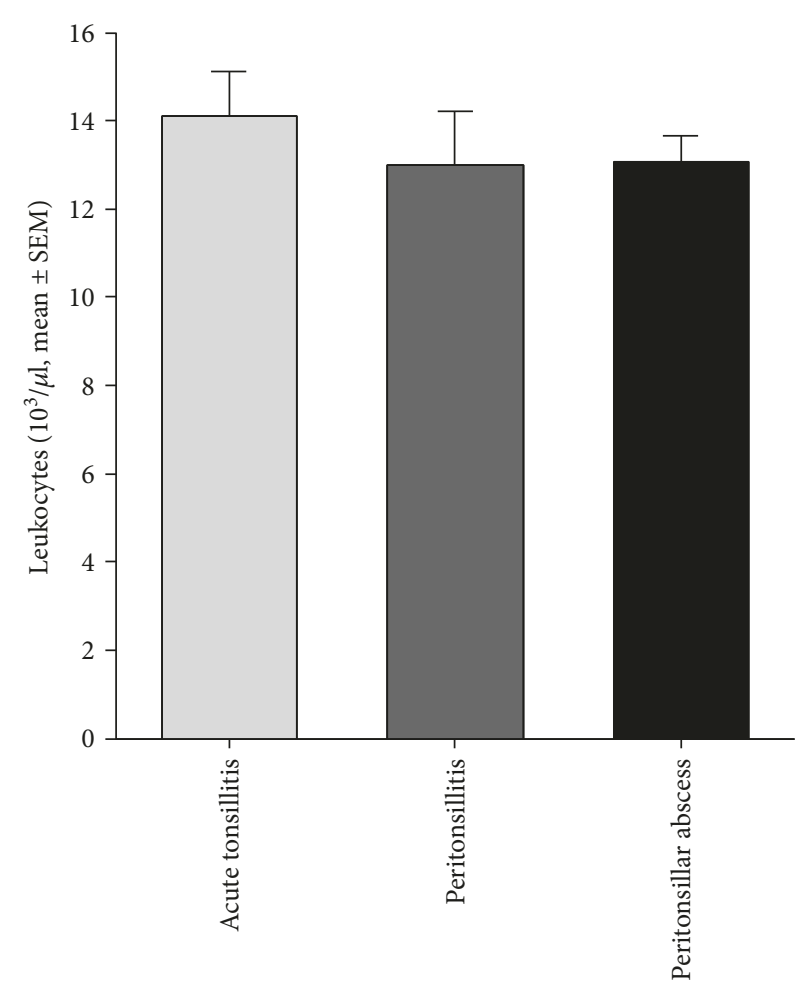

Diagnosis

(b)

FIgURE 3: CRP levels (a) and leukocytes (b) in patients with acute tonsillitis, peritonsillitis, and peritonsillar abscess (mean \pm SEM). No significant differences were observed between cohorts.

this is the first report of a correlation between elevated expression of S100A8/A9 and AT, PC, and PTA suggesting an important role of the innate immune response in disease development. As already mentioned above, S100A8/A9 has been described as a biomarker in several inflammatory and malignant diseases [24, 28-31]. In this study, we could quantify increased S100A8/A9 levels in patients' sera and saliva suffering from PTA.

Although increased levels of CRP $(>15.5 \mathrm{mg} / \mathrm{dl})$ and age $>35$ years are described to be predictors of retropharyngeal abscesses and necrotizing fasciitis, it is proven, and our data confirm, that neither CRP nor leukocytes in sera are appropriate markers to distinguish between PTA and AT [10]. Additionally, there are also no useful markers to differentiate between PTA and PC. Nevertheless, low correlations of S100A8/A9 levels in serum with CRP and leukocytes were detectable in patients with tonsillitis which is in concordance with recent findings in patients with myocardial infarction or rheumatoid arthritis $[32,33]$. Recently increased levels of IL-8 in the tissue of tonsils with PTA compared to tonsils derived from patients with recurrent tonsillitis were observed, and strong positive correlations of S100A8/A9 and IL-8 have been described in association with congestive heart failure $[34,35]$. Although we could observe a correlation between S100A8/A9 and IL-8 levels in the serum and saliva as well, neither IL-8 nor any other cytokine or chemokine we determined in the serum and saliva provides the potential to differentiate between acute tonsillitis, peritonsillitis, and peritonsillar abscess. Thus, we can assume S100A8/A9 to be a useful biomarker to identify patients with PTA.

Saliva of both patients and controls are macroscopically very inhomogeneous, and consequently, the content of S100A8/A9 shows a great variety in all cohorts. Although the data analysis has a high standard deviation, a comparative analysis was possible. Immunohistochemical findings revealed higher concentrations of S100A8/A9 in the tonsils of patients with PTA in contrast to hyperplastic tonsils without any history of tonsillitis. These findings impressively demonstrate a pivotal role in the pathomechanism as well as local expression and release of these DAMPs during PTA. However, the influence of S100A8/A9 on the development of PTA and its function regarding the tonsillar epithelium have not been elucidated so far. Hypothetically, S100A8/A9 is expressed by tonsil epithelial cells due to disruption of barrier function. A positive feedback mechanism with amplification of inflammation, induction of proinflammatory cytokine production, and simultaneous proliferation of keratinocytes as described in patients with systemic lupus erythematosus or psoriasis is assumable in tonsils and tonsillitis [36]. Thus, associated with leukocyte recruitment, pathogens could be eliminated and invasion could be averted [37]. Granulocyte migration through the gut wall into the feces allows determination of fecal S100A8/A9 in patients with inflammatory bowel diseases like Crohn's disease or appendicitis whereas release of S100A8/A9 by 


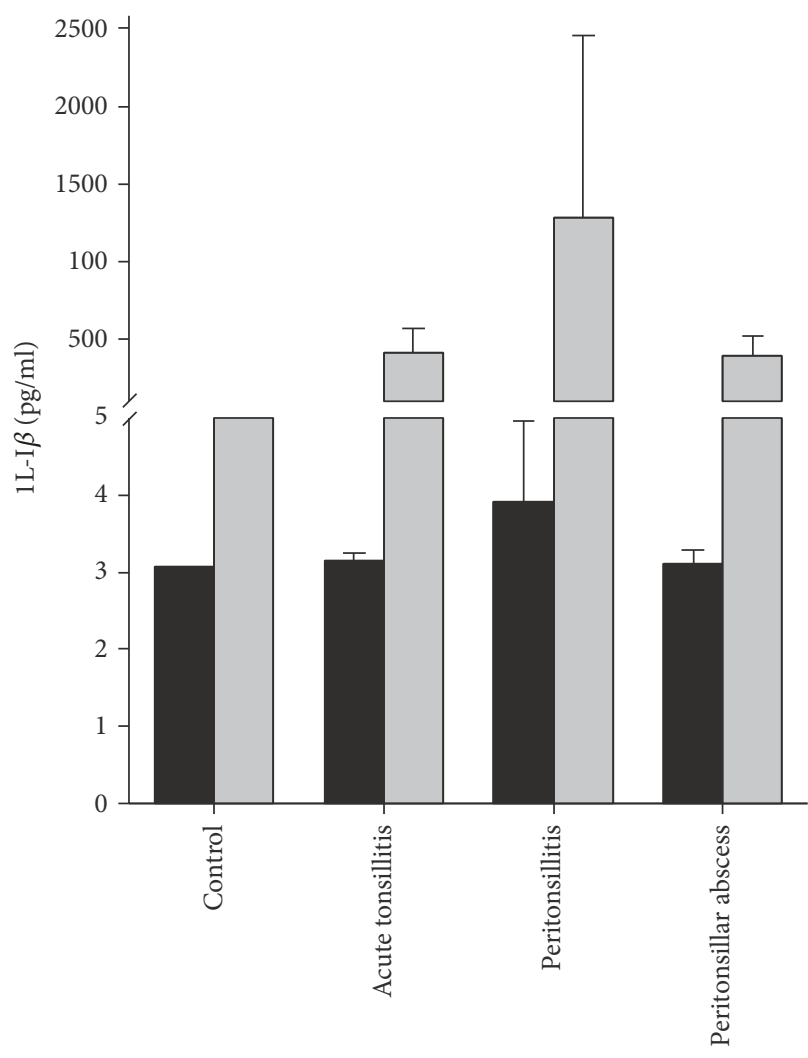

Diagnosis

Serum

Saliva

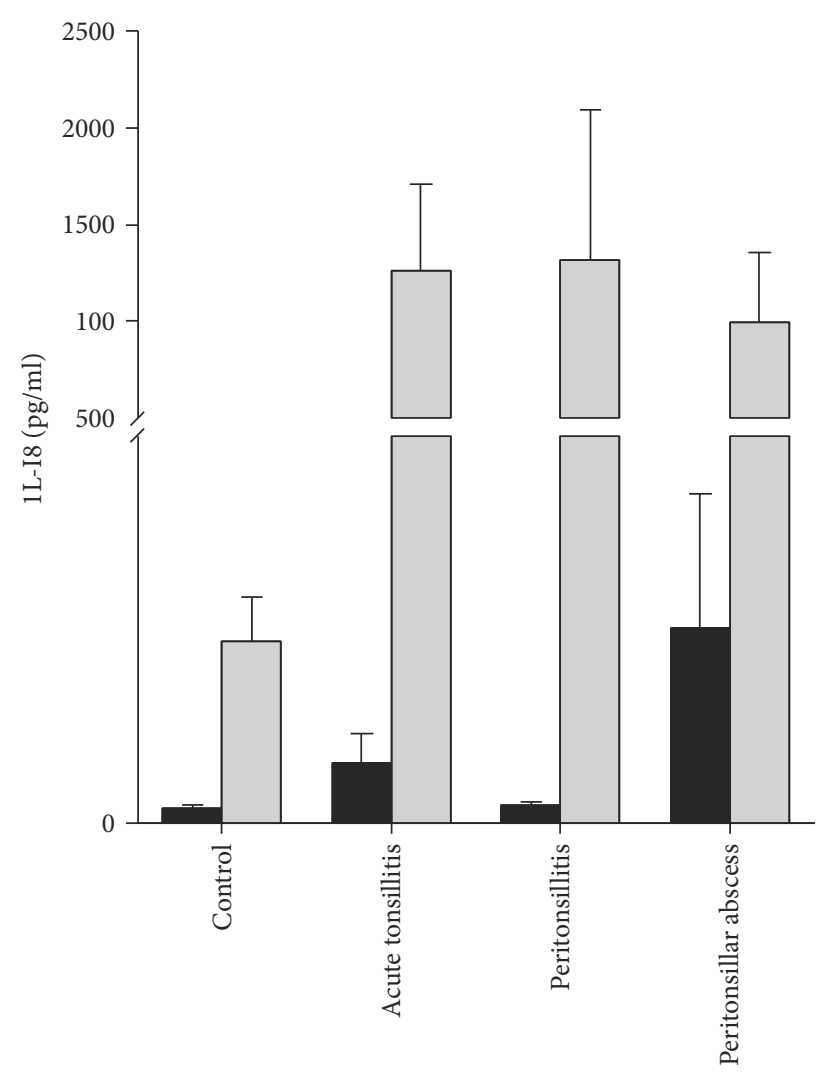

Diagnosis

Serum Saliva

(a)

(b)

FIGURE 4: Cytokines and chemokines in saliva and serum. Levels of IL-1 $\beta$ (a) and IL-8 (b) in controls, patients with acute tonsillitis, peritonsillitis, or peritonsillar abscess. No significant differences between the diagnosis groups were detectable $(p>0.05)$. Black bars $=$ serum levels, grey bars $=$ saliva levels, mean \pm SEM.

endothelial cells could be observed due to leukocyte interaction $[26,27,37,38]$. According to these findings, two possible mechanisms for elevated salivary levels of S100A8/A9 could be assumed: (1) active secretion by the tonsillar keratinocytes and (2) migration of activated leukocytes through the tonsillar epithelium.

Patients with peritonsillitis show symptoms suspicious of peritonsillar abscess but early, correct, and reliable diagnosis is important to determine the adequate treatment approach and to prevent the progress of the PTA attended with severe complications. The difficulty to differentiate between PTA and PC in clinical examination points out the necessity of an objective, reliable parameter [14]. Computed tomography scan (CT) was considered to be a helpful tool to distinguish between PC and PTA [39]. CT scan might enhance the diagnostic accuracy and avoid unnecessary drainage procedures but there are some limitations which should be taken into consideration [40]. Grant et al. evaluated the CT scan in children with PTA and observed a delay of less-invasive interventions and no influence of the CT scan on the intervention chosen by the clinician [41]. Furthermore, in $13 \%$ of the 3 to 5 -year-old children, common anesthesia or sedation was required for $\mathrm{CT}$ scan execution enhancing the risk of associated complications [41]. Due to the most important disadvantages of additional high costs, the radiation exposure and a specificity of just 50\%, the value of the CT scan as an appropriate tool to differentiate between PTA and PC is doubtful. Thus, CT scan should be limited to special, isolated cases and not be part of routine PC or PTA management, particularly in children [41]. Hence, the intraoral and transcutaneous ultrasound of the tonsil and the peritonsillar abscess were established as a cost-efficient and lower-risk method compared to CT scan [18]. Intraoral ultrasound was described to be more sensitive than the transcutaneous ultrasound (89-95\% versus 10-91\%), and specificity of intraoral ultrasound varied from 70 to $83 \%$ [18, 42-45]. Although the ultrasound represents a noninvasive and rapid tool to differentiate between PTA and PC, there exist also some limitations restricting the use of this methodology. Albeit, transoral ultrasound was described to be welltolerated; examination's result depends on the general cooperativeness as well as the physical condition of the patient [18]. Especially, children and compromised patients may not tolerate the procedure. Furthermore, in cases of severe trismus, entry of the probe into the oral cavity might be difficult or impossible [44]. Correct interpretation of the 


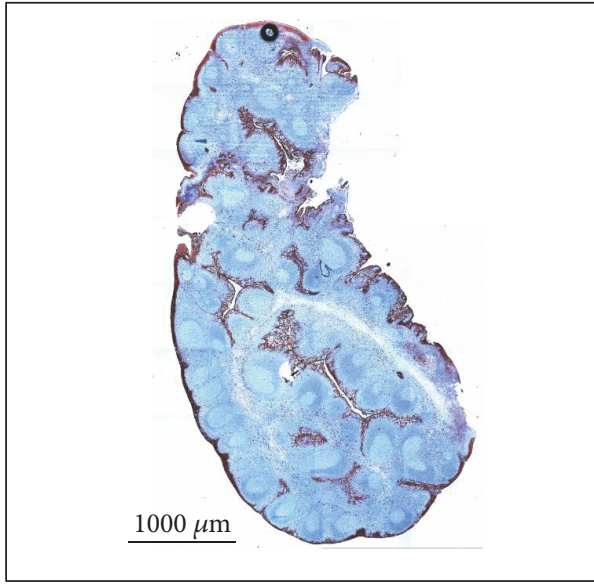

(a)

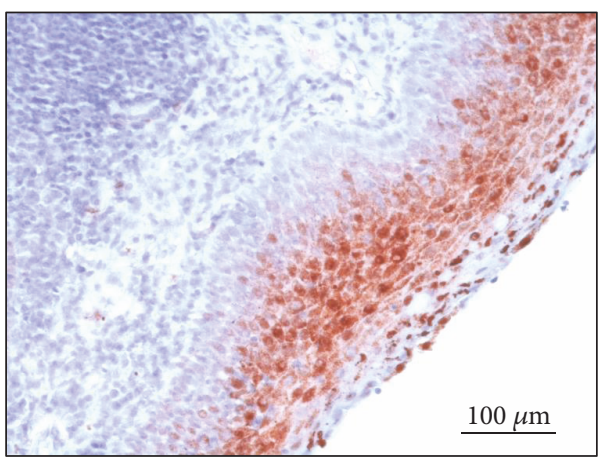

(c)

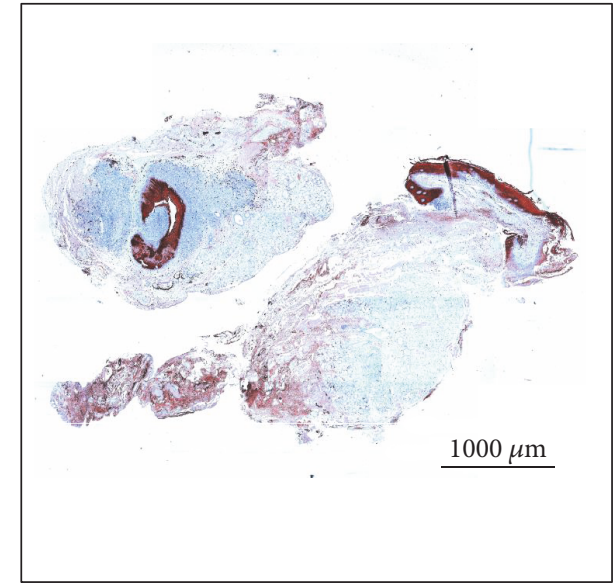

(b)

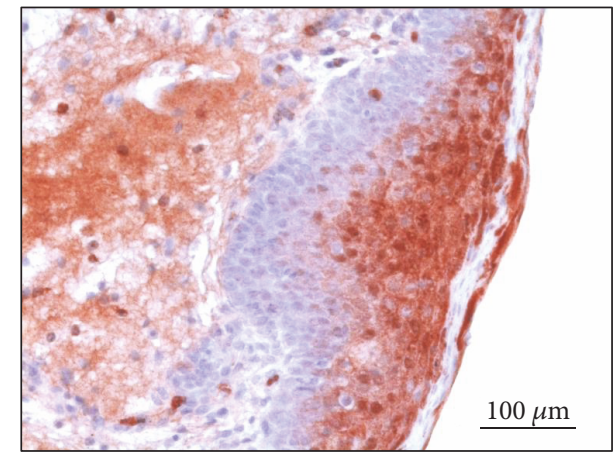

(d)

FIGURE 5: IHC staining for S100A8 of human palatine tonsils of patients with hypertrophic tonsils without any history of recurrent tonsillitis $(a, c)$ and suffering from peritonsillar abscess (b, d). S100A8 expression is limited to the surface and crypt epithelium of the hypertrophic tonsil. The tonsil of the PTA patient shows an intensified staining for S100A8 in the epithelium and the parenchyma. (a) and (b): MosaiX module, original magnification $\times 40$. (c) and (d): magnification $\times 200$.

TABle 1: PTA score: Addition of one point each for symptoms like halitosis, trismus, uvula edema, unilateral swelling of the arched palate, and S100A8/A9 levels in serum and saliva higher than the cut-off values results in a score with a range from 0 to 6 . High $S_{\text {PTA }}$ values are associated with an increased probability of PTA.

\begin{tabular}{lc}
\hline Symptoms & Points \\
\hline Halitosis & 1 \\
Trismus & 1 \\
Uvula edema & 1 \\
Unilateral swelling of the arched palate & 1 \\
Serum S100A8/A9 $>2550 \mathrm{ng} / \mathrm{ml}$ & 1 \\
Saliva S100A8/A9 $>8180 \mathrm{ng} / \mathrm{ml}$ & 1 \\
\hline
\end{tabular}

$0-2$ : acute tonsillitis/peritonsillitis; $\geq 3$ : peritonsillar abscess.

findings depends on the quality of ultrasound images as well as the advanced degree of technical and diagnostic expertise $[18,46]$. Hence, further limitation arises due to limited access to trained ultrasonographers, a significant interuser variability, and limited availability of adequate equipment $[18,43,44]$. As mentioned above, $50 \%$ of the patients with PTA were treated by nonotolaryngologists who were probably not familiar with ultrasound of the head and neck region, and ultrasound is not available at every ambulance $[13,47]$. Thus, for improving quality of care, it was the aim of the study to analyze the potential of S100A8/A9 as an objective marker to identify patients with peritonsillar abscess. We could show that the determination of S100A8/A9 levels in the serum and saliva in combination with symptoms suspicious of PTA is a helpful tool to distinguish between PTA and PC with a sensitivity of $92 \%$ and a specificity of $93 \%$. Sample acquisition is not associated with any risks or complaints for the patients, and data analysis is independent from the degree of expertise. Hence, the newly developed PTA score seems to be an appropriate screening method for peritonsillar abscess. It should be mentioned that both the S100A8/A9 level in serum and saliva should be included in the new PTA score for improving sensitivity and specificity. If S100A8/A9 levels were excluded, a cut-off value of 0.5 for the existence of PTA was determined which is inadequate for differentiation between acute tonsillitis, peritonsillitis, and peritonsillar abscess. Analyzing the power of the PTA score without S100A8/A9 to differentiate PTA from $\mathrm{PC}$ and AT revealed a cut-off value of 1.5 with a sensitivity of 0.89 but a low specificity of 0.71 . Thus, with a sensitivity of $92 \%$ and a specificity of $93 \%$, the PTA score including S100A8/A9 levels in the serum and saliva is more 


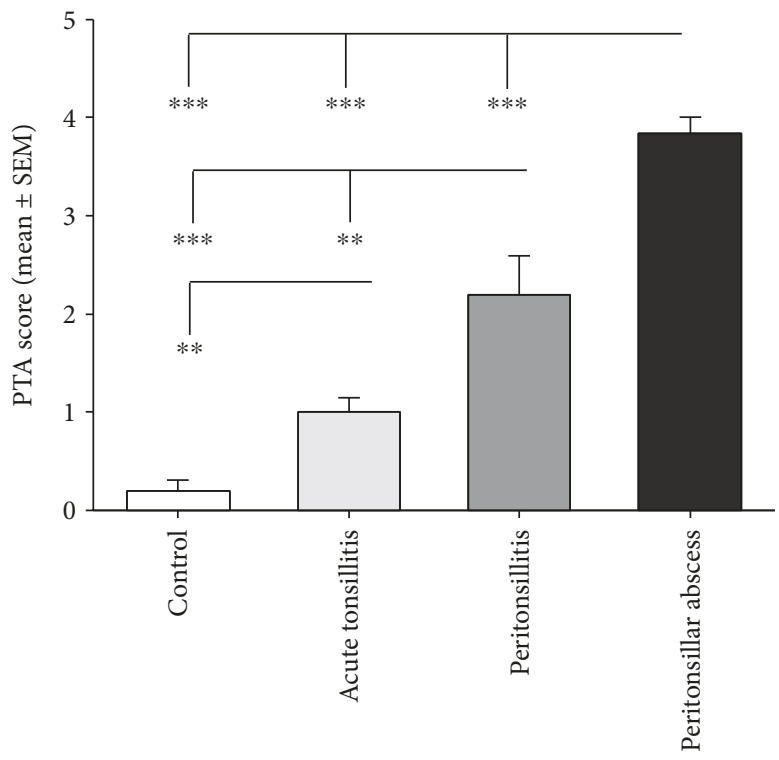

Diagnosis

(a)

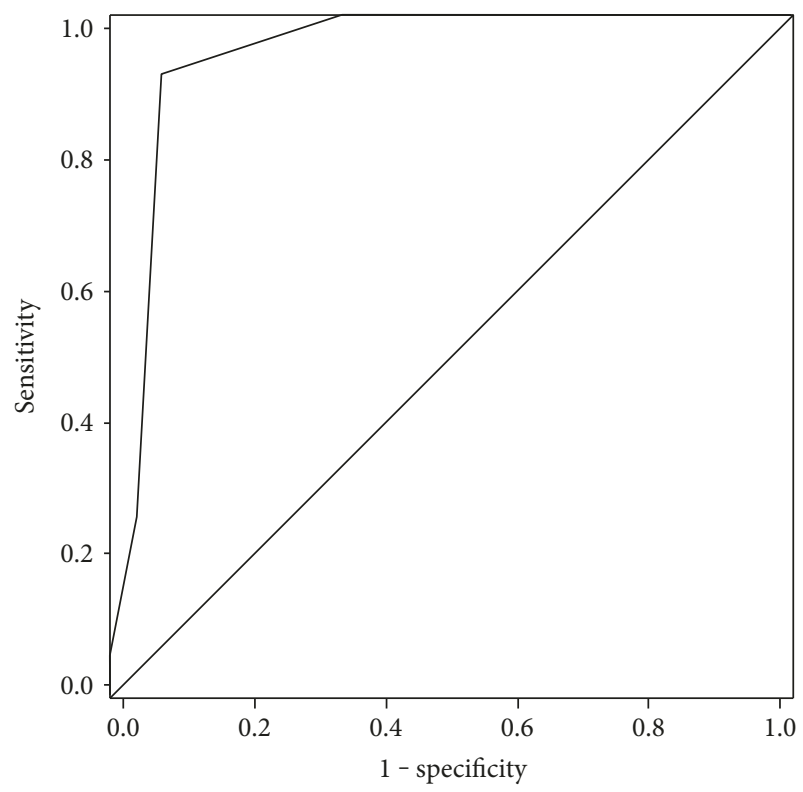

(b)

FIgure 6: PTA score $\left(S_{\text {PTA }}\right)$ was developed by the addition of one point each for symptoms like trismus, halitosis, uvula edema, unilateral swelling of the arched palate, S100A8/A9 $>2550 \mathrm{ng} / \mathrm{ml}$ in the serum, and S100A8/A9 > $8180 \mathrm{ng} / \mathrm{ml}$ in the saliva. Patients with acute tonsillitis, peritonsillitis, and peritonsillar abscess show significant higher $S_{\text {PTA }}$ values in comparison with the controls. Furthermore, a significant difference of $S_{\text {PTA }}$ values between the PTA and the PC cohort was detectable (a). ROC analysis of the PTA score revealed a cutoff value of $S_{\mathrm{PTA}}=2.5$ (sensitivity $=0.92$, specificity $=0.93, p<0.001$ ) to identify patients suffering from PTA (black: ROC curve in black, grey: diagonal association line) $\left({ }^{* *} p<0.01\right.$, and $\left.{ }^{* * *} p<0.001\right)$.

TABle 2: Probability of PTA in dependence on the $S_{\mathrm{PTA}}$ values. The likelihood for PTA increases with higher PTA score values. For $S_{\text {PTA }}$ values $\geq 3$, the overall probability of PTA is about $89 \%$.

\begin{tabular}{lcc}
\hline PTA score value & Probability of PTA & $n$ \\
\hline 0 & $0 \%$ & 21 \\
1 & $0 \%$ & 16 \\
2 & $18 \%$ & 17 \\
3 & $92 \%$ & 12 \\
$\geq 4$ & $88 \%$ & 25 \\
\hline
\end{tabular}

reliable. Additionally, as mentioned above, increased levels of S100A8/A9 could be observed in serum of patients with varied diseases concerning the bowel, the joints, the heart, the skin, and multiple other organs, and enhanced S100A8/A9 levels have been observed in crevicular fluid of patients suffering from periodontitis [26, 27, 34, 48, 49]. Therefore, including typical symptoms of PTA, the PTA score indicates the probable association between elevated S100A8/A9 levels and PTA and is more reliable than the determination of S100A8/A9 levels solely.

However, this methodology also has its limitations. S100A8/A9 values were determined by ELISA which is time-consuming and not suitable for the outpatient consultation. Hence, a rapid test for the immediate and easy measurement of salivary and serum S100A8/A9 levels which can be performed by every person independent from degree of expertise, with a low interuser variability within a short time, is under development. Another limitation of our study is an incertitude concerning the diagnosis of peritonsillitis. Although needle aspiration or incision revealed no pus and patients showed a good response to intravenous antibiotics, an abscess could not be certainly excluded.

Further randomized clinical trials with bigger cohorts are necessary to verify the importance, sensitivity, specificity, and accuracy of the PTA score as a prognostic and diagnostic parameter in the future. Particularly, the possibility of the new developed $S_{\mathrm{PTA}}$ including S100A8/A9 to identify patients who might profit from medical treatment or whether tonsillectomy or abscess relief is required has to be elucidated. Furthermore, the influence of S100A8/A9 and the associated immune cells on abscess formation needs further investigations.

\section{Conclusion}

The elevated levels of S100A8/A9 in the sera and saliva of patients with peritonsillar abscess represent a new 
application of the well-established biomarker calprotectin. Hence, ascertainment of S100A8/A9 levels in the serum and saliva and application of the new PTA score is a useful diagnostic tool to differentiate between peritonsillar abscess, peritonsillar cellulitis, or acute tonsillitis during urgent outpatient consultation.

\section{Conflicts of Interest}

The authors declare that they have no conflict of interests.

\section{Acknowledgments}

Christoph Spiekermann is supported by a fellowship of the medical faculty at the University of Muenster, Germany. This work was supported by Grants of the IMF (Innovative Medizinische Forschung) of the medical faculty at the University of Muenster to Christoph Spiekermann (SP 2115 11), the Interdisciplinary Center of Clinical Research at the University of Muenster to Thomas Vogl and Johannes Roth (Vo2/014/09, Ro2/003/15), the German Research Foundation (DFG) CRC 1009 B8 and B9 to Thomas Vogl and Johannes Roth, and by the Federal Ministry of Education and Research (BMBF), project AID-NET to Johannes Roth. This work was supported by a fellowship of the Graduate School of the Cells-in-Motion Cluster of Excellence (EXC 1003-CiM), University of Muenster, Germany to Antonella Russo. The authors thank A. Dietrich, M. Menke, C. Terwesten-Solé. A. Stadtbäumer, H. Berheide, and H. Hater for excellent technical assistance and acknowledge the support from the Open Access Publication Fund of University of Muenster.

\section{References}

[1] M. J. van Kempen, G. T. Rijkers, and P. B. Van Cauwenberge, "The immune response in adenoids and tonsils," International Archives of Allergy and Immunology, vol. 122, pp. 8-19, 2000.

[2] A. Komorowska, J. Komorowski, M. Banasik, P. Lewkowicz, and $\mathrm{H}$. Tchorzewski, "Cytokines locally produced by lymphocytes removed from the hypertrophic nasopharyngeal and palatine tonsils," International Journal of Pediatric Otorhinolaryngology, vol. 69, pp. 937-941, 2005.

[3] M. Kawabata, M. Umakoshi, T. Makise et al., "Clinical classification of peritonsillar abscess based on CT and indications for immediate abscess tonsillectomy," Auris Nasus Larynx, vol. 43, pp. 182-186, 2016.

[4] D. L. Souza, D. Cabrera, W. I. Gilani et al., "Comparison of medical versus surgical management of peritonsillar abscess: a retrospective observational study," The Laryngoscope, vol. 126, pp. 1529-1534, 2016.

[5] R. Vaikjarv, P. Kasenomm, L. Jaanimae et al., "Microbiology of peritonsillar abscess in the South Estonian population," Microbial Ecology in Health \& Disease, vol. 27, article 27787, 2016.

[6] V. Passy, "Pathogenesis of peritonsillar abscess," The Laryngoscope, vol. 104, pp. 185-190, 1994.

[7] I. Brook, E. H. Frazier, and D. H. Thompson, "Aerobic and anaerobic microbiology of peritonsillar abscess," The Laryngoscope, vol. 101, pp. 289-292, 1991.
[8] H. Jousimies-Somer, S. Savolainen, A. Makitie, and J. Ylikoski, "Bacteriologic findings in peritonsillar abscesses in young adults," Clinical Infectious Diseases, vol. 16, Supplement 4, pp. S292-S298, 1993.

[9] I. Brook, "Microbiology and management of peritonsillar, retropharyngeal, and parapharyngeal abscesses," Journal of Oral and Maxillofacial Surgery, vol. 62, pp. 1545-1550, 2004.

[10] C. Gahleitner, B. Hofauer, T. Stark, and A. Knopf, "Predisposing factors and management of complications in acute tonsillitis," Acta Oto-Laryngologica, vol. 136, pp. 964-968, 2016.

[11] E. L. Powell, J. Powell, J. R. Samuel, and J. A. Wilson, “A review of the pathogenesis of adult peritonsillar abscess: time for a re-evaluation," The Journal of Antimicrobial Chemotherapy, vol. 68, pp. 1941-1950, 2013.

[12] F. S. Herzon, "Harris P. Mosher Award thesis. Peritonsillar abscess: incidence, current management practices, and a proposal for treatment guidelines," The Laryngoscope, vol. 105, pp. 1-17, 1995.

[13] F. S. Herzon, "Permucosal needle drainage of peritonsillar abscesses. A five-year experience," Archives of Otolaryngology - Head and Neck Surgery, vol. 110, pp. 104-105, 1984.

[14] D. Ophir, J. Bawnik, Y. Poria, M. Porat, and G. Marshak, "Peritonsillar abscess. A prospective evaluation of outpatient management by needle aspiration," Archives of Otolaryngology - Head and Neck Surgery, vol. 114, pp. 661-663, 1988.

[15] S. Savolainen, H. R. Jousimies-Somer, A. A. Makitie, and J. S. Ylikoski, "Peritonsillar abscess. Clinical and microbiologic aspects and treatment regimens," Archives of Otolaryngology Head and Neck Surgery, vol. 119, pp. 521-524, 1993.

[16] R. F. Johnson, M. G. Stewart, and C. C. Wright, "An evidencebased review of the treatment of peritonsillar abscess," Otolaryngology-Head and Neck Surgery, vol. 128, pp. 332-343, 2003.

[17] I. Mohamad and A. Yaroko, "Peritonsillar swelling is not always quinsy," Malaysian Family Physician, vol. 8, pp. 53$55,2013$.

[18] M. H. Froehlich, Z. Huang, and B. K. Reilly, "Utilization of ultrasound for diagnostic evaluation and management of peritonsillar abscesses," Current Opinion in Otolaryngology \& Head and Neck Surgery, vol. 25, pp. 163-168, 2017.

[19] K. Strupat, H. Rogniaux, A. Van Dorsselaer, J. Roth, and T. Vogl, "Calcium-induced noncovalently linked tetramers of MRP8 and MRP14 are confirmed by electrospray ionizationmass analysis," Journal of the American Society for Mass Spectrometry, vol. 11, pp. 780-788, 2000.

[20] T. Vogl, J. Roth, C. Sorg, F. Hillenkamp, and K. Strupat, "Calcium-induced noncovalently linked tetramers of MRP8 and MRP14 detected by ultraviolet matrix-assisted laser desorption/ionization mass spectrometry," Journal of the American Society for Mass Spectrometry, vol. 10, pp. 1124-1130, 1999.

[21] S. K. Fassl, J. Austermann, O. Papantonopoulou et al., "Transcriptome assessment reveals a dominant role for TLR4 in the activation of human monocytes by the alarmin MRP8," The Journal of Immunology, vol. 194, pp. 575-583, 2015.

[22] D. Foell, H. Wittkowski, T. Vogl, and J. Roth, "S100 proteins expressed in phagocytes: a novel group of damage-associated molecular pattern molecules," Journal of Leukocyte Biology, vol. 81, pp. 28-37, 2007.

[23] T. Vogl, K. Tenbrock, S. Ludwig et al., "Mrp8 and Mrp14 are endogenous activators of Toll-like receptor 4, promoting lethal, endotoxin-induced shock," Nature Medicine, vol. 13, pp. 1042-1049, 2007. 
[24] M. P. Manitz, B. Horst, S. Seeliger et al., "Loss of S100A9 (MRP14) results in reduced interleukin-8-induced CD11b surface expression, a polarized microfilament system, and diminished responsiveness to chemoattractants in vitro," Molecular and Cellular Biology, vol. 23, pp. 1034-1043, 2003.

[25] A. M. Healy, M. D. Pickard, A. D. Pradhan et al., "Platelet expression profiling and clinical validation of myeloid-related protein-14 as a novel determinant of cardiovascular events," Circulation, vol. 113, pp. 2278-2284, 2006.

[26] D. Foell, H. Wittkowski, Z. Ren et al., "Phagocyte-specific S100 proteins are released from affected mucosa and promote immune responses during inflammatory bowel disease," The Journal of Pathology, vol. 216, pp. 183-192, 2008.

[27] M. Frosch, A. Strey, T. Vogl et al., "Myeloid-related proteins 8 and 14 are specifically secreted during interaction of phagocytes and activated endothelium and are useful markers for monitoring disease activity in pauciarticular-onset juvenile rheumatoid arthritis," Arthritis and Rheumatism, vol. 43, pp. 628-637, 2000.

[28] D. Moris, E. Spartalis, A. Angelou et al., "The value of calprotectin S100A8/A9 complex as a biomarker in colorectal cancer: a systematic review," Journal of Balkan Union of Oncology, vol. 21, pp. 859-866, 2016.

[29] L. Wang, E. W. Chang, S. C. Wong, S. M. Ong, D. Q. Chong, and K. L. Ling, "Increased myeloid-derived suppressor cells in gastric cancer correlate with cancer stage and plasma S100A8/A9 proinflammatory proteins," Journal of Immunology, vol. 190, pp. 794-804, 2013.

[30] D. Foell, M. Frosch, C. Sorg, and J. Roth, "Phagocyte-specific calcium-binding S100 proteins as clinical laboratory markers of inflammation," Clinica Chimica Acta, vol. 344, pp. 37-51, 2004.

[31] J. M. Ehrchen, C. Sunderkotter, D. Foell, T. Vogl, and J. Roth, "The endogenous Toll-like receptor 4 agonist S100A8/S100A9 (calprotectin) as innate amplifier of infection, autoimmunity, and cancer," Journal of Leukocyte Biology, vol. 86, pp. 557566, 2009.

[32] T. Katashima, T. Naruko, F. Terasaki et al., "Enhanced expression of the S100A8/A9 complex in acute myocardial infarction patients," Circulation Journal, vol. 74, pp. 741-748, 2010.

[33] K. Y. Kang, J. W. Woo, and S. H. Park, "S100A8/A9 as a biomarker for synovial inflammation and joint damage in patients with rheumatoid arthritis," The Korean Journal of Internal Medicine, vol. 29, pp. 12-19, 2014.

[34] L. P. Ma, E. Haugen, M. Ikemoto, M. Fujita, F. Terasaki, and $\mathrm{M} . \mathrm{Fu}$, "S100A8/A9 complex as a new biomarker in prediction of mortality in elderly patients with severe heart failure," International Journal of Cardiology, vol. 155, pp. 2632, 2012.

[35] C. Rudack, S. Jorg, and F. Sachse, "Biologically active neutrophil chemokine pattern in tonsillitis," Clinical and Experimental Immunology, vol. 135, pp. 511-518, 2004.

[36] H. A. Kim, J. H. Han, W. J. Kim et al., "TLR4 endogenous ligand S100A8/A9 levels in adult-onset Still's disease and their association with disease activity and clinical manifestations," International Journal of Molecular Sciences, vol. 17, 2016.

[37] M. Pruenster, A. R. Kurz, K. J. Chung et al., "Extracellular MRP8/14 is a regulator of $\beta 2$ integrin-dependent neutrophil slow rolling and adhesion," Nature Communications, vol. 6, p. $6915,2015$.
[38] J. F. Bealer and M. Colgin, "S100A8/A9: a potential new diagnostic aid for acute appendicitis," Academic Emergency Medicine, vol. 17, pp. 333-336, 2010.

[39] M. Sakaguchi, S. Sato, S. Asawa, and K. Taguchi, "Computed tomographic findings in peritonsillar abscess and cellulitis," The Journal of Laryngology and Otology, vol. 109, pp. 449451, 1995.

[40] K. S. Patel, S. Ahmad, G. O'Leary, and M. Michel, "The role of computed tomography in the management of peritonsillar abscess," Otolaryngology-Head and Neck Surgery, vol. 107, pp. 727-732, 1992.

[41] M. C. Grant and J. L. Guarisco, "Association between computed tomographic scan and timing and treatment of peritonsillar abscess in children," JAMA OtolaryngologyHead \& Neck Surgery, vol. 142, pp. 1051-1055, 2016.

[42] A. R. Buckley, E. H. Moss, and A. Blokmanis, "Diagnosis of peritonsillar abscess: value of intraoral sonography," American Journal of Roentgenology, vol. 162, pp. 961-964, 1994.

[43] E. B. Strong, P. J. Woodward, and L. P. Johnson, "Intraoral ultrasound evaluation of peritonsillar abscess," The Laryngoscope, vol. 105, pp. 779-782, 1995.

[44] S. Nogan, D. Jandali, M. Cipolla, and B. DeSilva, "The use of ultrasound imaging in evaluation of peritonsillar infections," The Laryngoscope, vol. 125, pp. 2604-2607, 2015.

[45] T. Boesen and F. Jensen, "Preoperative ultrasonographic verification of peritonsillar abscesses in patients with severe tonsillitis," European Archives of Oto-Rhino-Laryngology, vol. 249, pp. 131-133, 1992.

[46] M. T. Fordham, A. N. Rock, A. Bandarkar et al., "Transcervical ultrasonography in the diagnosis of pediatric peritonsillar abscess," The Laryngoscope, vol. 125, pp. 2799-2804, 2015.

[47] F. S. Herzon and A. D. Martin, "Medical and surgical treatment of peritonsillar, retropharyngeal, and parapharyngeal abscesses," Current Infectious Disease Reports, vol. 8, pp. 196-202, 2006.

[48] A. J. Kim, H. Ro, H. Kim et al., "Klotho and S100A8/A9 as discriminative markers between pre-renal and intrinsic acute kidney injury," PLoS One, vol. 11, article e0147255, 2016.

[49] Y. Zhan, R. Lu, H. Meng, X. Wang, and J. Hou, "Platelet activation and platelet-leukocyte interaction in generalized aggressive periodontitis," Journal of Leukocyte Biology, vol. 100, pp. 1155-1166, 2016. 


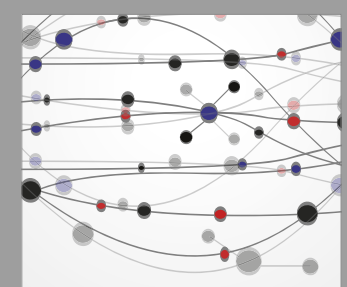

The Scientific World Journal
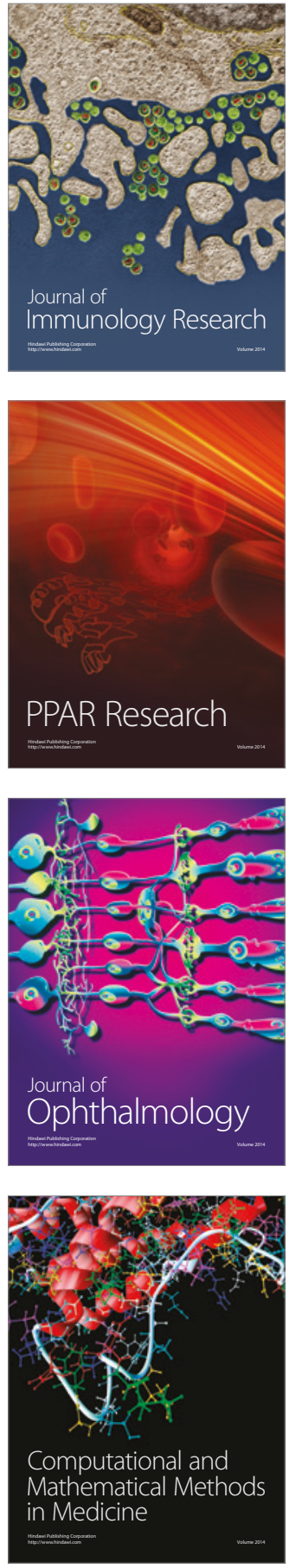

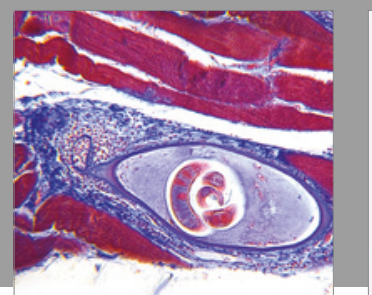

Gastroenterology Research and Practice
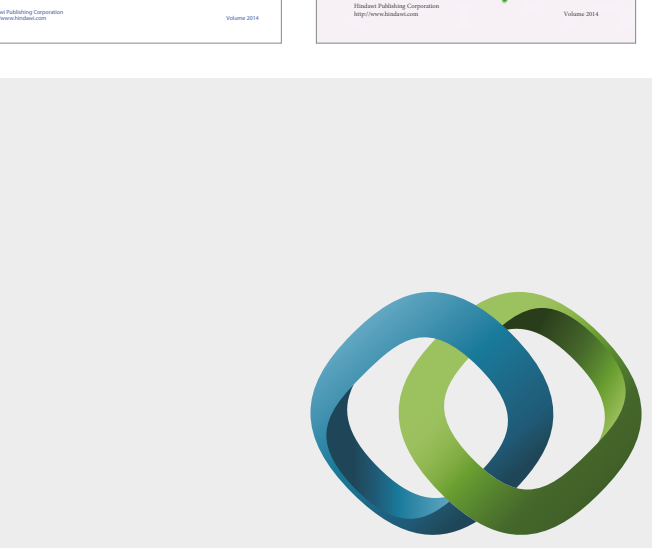

\section{Hindawi}

Submit your manuscripts at

https://www.hindawi.com
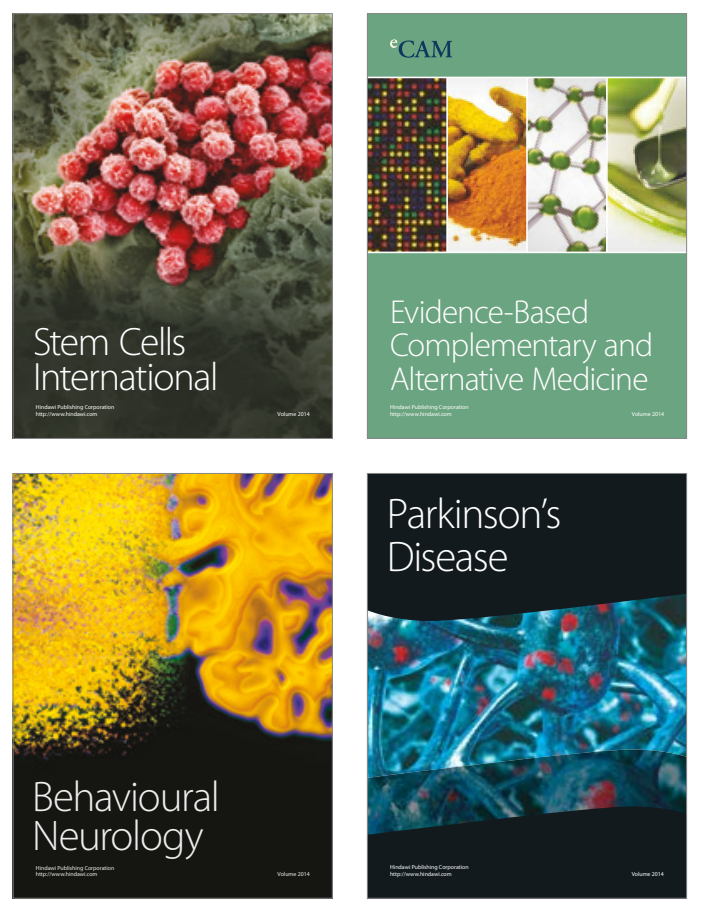
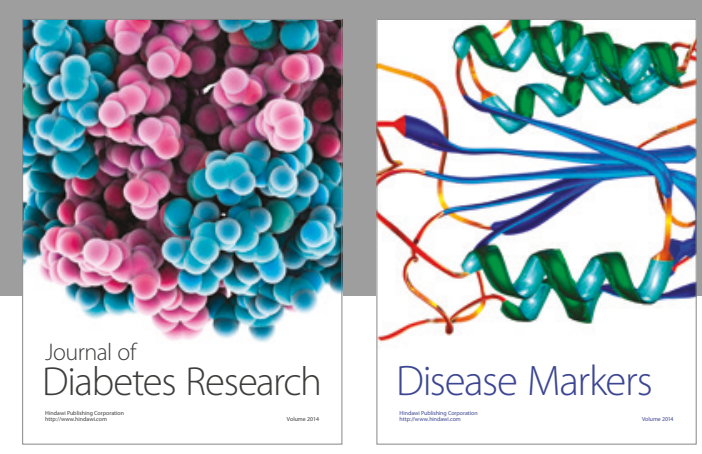

Disease Markers
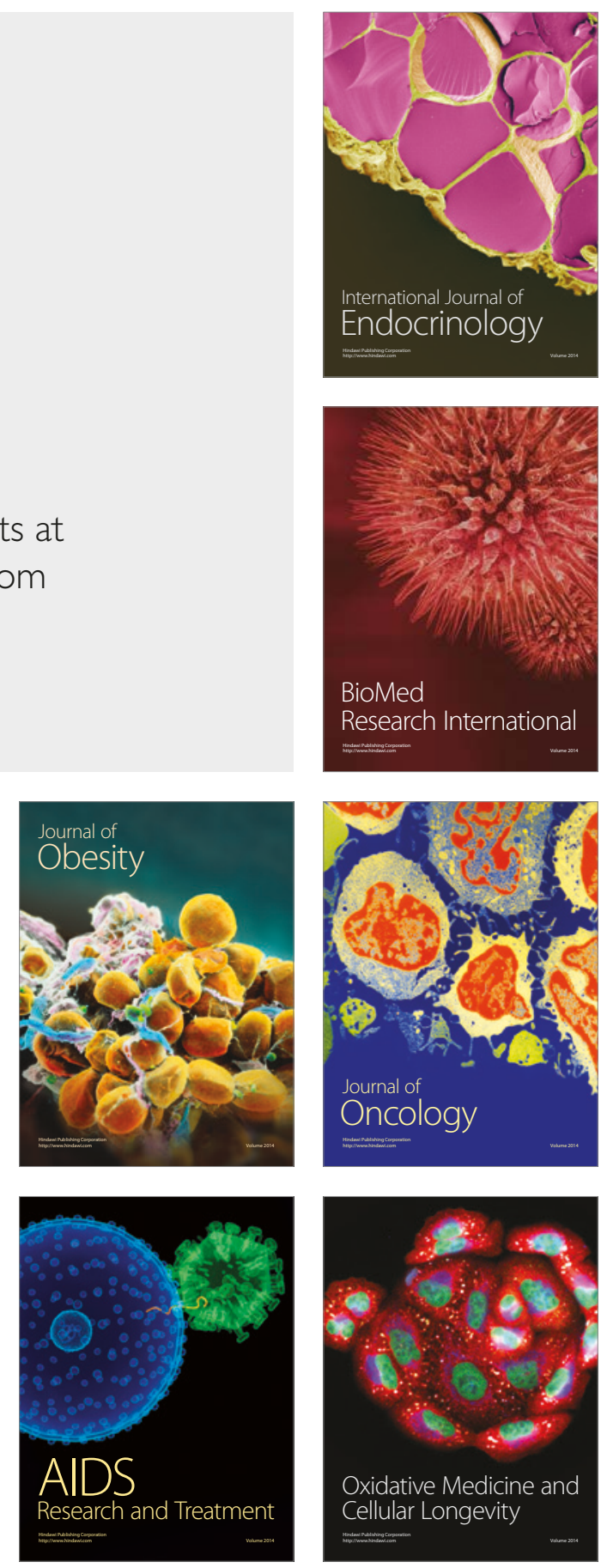